\title{
Factors of work environment hazardous for health in opinions of employees working underground in the 'Bogdanka' coal mine
}

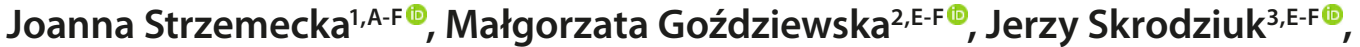 \\ Elżbieta Monika Galińska ${ }^{4, E-F \circledast, ~ S t a n i s ł a w ~ L a c h o w s k i ~}{ }^{5, C-E \odot ~}$ \\ ${ }^{1}$ Pope John Paul II State School of Higher Education in Biala Podlaska: Biala Podlaska, Poland \\ ${ }^{2}$ Department of Medical Anthropology, Institute of Rural Health, Lublin, Poland \\ ${ }^{3}$ Department of Foreign Languages, Józef Piłsudski University of Physical Education in Warsaw, Faculty of Physical \\ Education and Sport in Biała Podlaska, Poland \\ ${ }^{4}$ Department of Biological Health Hazards and Parasitology, Institute of Rural Health, Lublin, Poland \\ ${ }^{5}$ Maria Curie-Sklodowska University, Lublin, Poland \\ A - Research concept and design, B - Collection and/or assembly of data, C - Data analysis and interpretation, \\ $D$ - Writing the article, $E$ - Critical revision of the article, F - Final approval of article
}

Strzemecka J, Goździewska M, Skrodziuk J, Galińska EM, Lachowski S. Factors of work environment hazardous for health in opinions of employees working underground in the 'Bogdanka' coal mine. Ann Agric Environ Med. 2019; 26(3): 409-414. doi: 10.26444/aaem/106224

\begin{abstract}
Introduction. Employees performing work underground in coal mines are exposed to the effect of many hazardous factors in their work environment which negatively affect their health.

Objective. The objective of the study was to recognize the opinions of employes working underground in one of the coal mines concerning the occurrence of factors hazardous for health in their work environment.

Materials and method. The study was conducted in a group of 700 persons working underground in the 'Bogdanka' coal mine in Łęczna (Eastern Poland). The study was carried out using a questionnaire. The results were statistically analyzed using software STATISTICA v. 7.1.

Results. The vast majority of respondents (approximately $80 \%$ ) reported that noise and dustiness at their workplace create risk for their health. More than a half of them mentioned that the microclimate in the mine threatens their health (high humidity and high temperature), and a half of respondents indicated vibration and poor lighting. The greatest differences of opinions concerning the effect of hazardous factors on health of persons employed in the mine were observed in the sub-groups distinguished according to the work position. Health risk at a workplace was most often identified by those employed as miners.

Conclusions. Among actions reducing the negative effect of the work environment on health is the introduction of new, safer technologies of coal mining. Also, the human factor is very important for work safety in mining, including the proper preparation of employees who undertake work in a mine. It is recommended that new, more effective educational programmes are implemented in the area of Occupational Safety and Health (OSH) at workplaces.
\end{abstract}

\section{Key words}

health hazards, work in mining, $\mathrm{OSH}$, work safety

\section{INTRODUCTION}

In many developing countries, the mining industry is an important and rapidly developing sector of the economy. According to the International Labour Organization (ILO), this sector is one of the most dangerous worldwide $[1,2]$, and is also considered as dangerous and risky by the workers employed in mines $[1,3]$. The phenomenon of accident rates at work in mining is the highest, compared to other sectors of economy, and especially high in traditional and small mines $[4,5]$. The majority of workplaces in mining are related with physical work and exposure of workers to various health hazards on the part of such factors as: extreme temperatures, humidity, noise, vibration, and also prolonged working hours and shift work $[4,6,7]$. Noise at workplaces in mines is considered as the main risk factor causing hearing loss in

Address for correspondence: Małgorzata Goździewska, Department of Medical Anthropology, Institute of Rural Health, Lublin, Poland

E-mail: malgorzata.gozdziewska@gmail.com

Received: 15.03.2019; accepted: 08.04.2019; first published: 11.04.2019 employees [8]. Another factor unfavourable for the health of miners is coal dust. Its common occurrence in a coal mine is the cause of lung diseases, including pneumoconiosis, an incurable occupational disease of workers employed underground $[9,10,11]$. In coal mines there are also specific microclimatic conditions - high temperature and humidity. In these conditions it is difficult to achieve thermal comfort which is expressed by satisfaction with the thermal environment $[12,13,14]$. Environmental conditions required for the comfort of employees may differ between individuals, because people differ both physiologically and psychologically.

High traumatism at work in the mining industry results mainly from the lack of balance between unfavourable work conditions and the capability of a worker to cope with them. Unfavourable work conditions cover a wide range of elements related primarily with exposure to biochemical and physical factors. In addition, psychological predispositions and worker's competences to undertake specified tasks are very important in the assessment of safety at a workplace. 
This concerns, among other things, the skills of assuming an appropriate body position, materials and tools, proper work organization, as well as skills of coping with pressure on the part of management associated with striving for the achievement of the expected effects of production [15-23].

In the United States, the National Occupational Mortality Surveillance System was implemented in order to estimate the most frequent causes of death among MNM (metal and non-metal) miners. The analyses performed within the System demonstrated that the five most frequent causes of death are: heart diseases, cancer, chronic lower respiratory disease, cerebrovascular disease and unintentional body injuries [24, 25].

In turn, among the total number of diseases and injuries among MNM miners reported during the period 2007-2011 to the Mine Safety and Health Administration, the most frequent were: unclassified diseases (266); dust in the eyes (185); arthritis (182), hearing loss (142); poisonings (91); and exposure to heat/heat illnesses $(63)[25,26]$.

In the 'Bogdanka' coal mine, according to the Management Report on the activity of the Lublin Coal Mine Bogdanka S.A. for the period from 1 January 2009 - 31 December 2009, in the item concerning work conditions we may read that due to the character of the economic activity of the Company, the workers employed in the mine, especially underground, are exposed to a number of hazards, including mainly natural and technical hazards. Work in mining conditions is also related with exposure to hazardous and arduous factors of the work environment occurring at workplaces. Hazardous factors at a workplace include: dustiness, noise and mechanical vibration. The main arduous factors occurring in the coal mine, and precisely during operation of the mine underground are: microclimate (temperature, humidity, pressure, intensity of cooling), lighting, and an excessive physical effort [27].

Considering the specificity of work in coal mines, related with the occurrence of many hazards to the health of persons who work there and high accident and injury rates at these workplaces, an interesting problem is the evaluation of the level of awareness of risk for life and health among workers. The objective of the study is the recognition of opinions of employees working underground in the 'Bogdanka' coal mine concerning the occurrence of factors hazardous for health at their work environment.

\section{MATERIALS AND METHOD}

The basis for achieving the adopted aim of the study was an investigation carried out in the Coal Mine 'Bogdanka' in Łęczna, located in Eastern Poland. Employees who performed shift work, irrespective of their work position, participated in the survey. Anonymous questionnaires were completed by 700 workers who, during the period from January-April 2006, participated in obligatory courses conducted at their place of work. The questionnaire used in the study was constructed by the author. The proper study was preceded by a pilot study in a group of 50 respondents in order to test the correctness of the research instrument. The pilot study enabled development of the final version of the questionnaire. The main part of the questionnaire consisted of items concerning the respondents' opinions pertaining to the occurrence of hazardous factors at their workplaces, such as: dust, vibration, humidity of the air, high temperature, poor lighting, physical load, emotional load, forced body position, and presence of chemical substances. In addition, the questionnaire contained items concerning the respondents' demographic characteristics (age, education, period of employment), and characteristics of the work position held. In analyses, the data concerning the respondents' characteristics functioned as independent variables. The results obtained were analyzed statistically. The significance of the differences between two variables was investigated using the chi-square test for independence. For small numbers, the Yate's correction was applied. 5\% inference error was adopted. The $\mathrm{p}$ values $\mathrm{p}<0.05$ were considered statistically significant. Statistical analysis was performed using the software STATISTICA v. 7.1 (StatSoft, Polska).

\section{RESULTS}

The study included 700 males, working underground in shifts in the 'Bogdanka' coal mine. The respondents' age varied the largest number of them - a half (49.7\%), were aged 41-50, nearly one-third were aged from $31-40$ (29.6\%), the smallest group were the youngest respondents aged $21-30$ (16\% of the total number of workers in the study), while those who were the oldest (51 and over) $-4.7 \%$. The majority of respondents had a low level of education - elementary vocational or primary (57.0\%). Nearly one-third of the examined workers completed secondary school (29.9\%), and the remainder $(13.1 \%)$ graduated from university at the licentiate or Master levels.

The majority of respondents were employed at the work position of a miner (74.0\%). The smallest group were employees at work positions of mining supervision (6.1\%), whereas the remainder (19.9\%) declared working underground, but at other workplaces than a miner, e.g. electricians. Unfortunately, due to the diversity of these occupations and small numbers in individual groups, all workers performing work underground without direct relation with mining were qualified into one category - 'others'.

Within the conducted study, the employees of the 'Bogdanka' mine were asked to indicate the elements of the environment which exert a negative effect on their state of health. They were presented with 10 factors for evaluation of the work environment occurring in the mine underground which may unfavourably affect health. The replies obtained showed that in the opinions of the employees of the 'Bogdanka' coal mine, noise and dustiness created the greatest risk for health. The majority of respondents (approximately $80 \%$ of the total number) reported these factors (Fig. 1). More than a half of respondents perceived that the microclimate in the mine threatens their health, i.e. high humidity (56.7\%), and high temperature (56.9\%). A half of respondents mentioned the following factors as being hazardous for health: vibration (50.7\%), poor lighting (49.9\%), and high physical load (45.3\%). A considerably lower percentage of respondents indicated forced body position at work as a health risk factor (31.3\%), also emotional load (27.6\%), and chemical substances present at the workplace (Fig.1).

In further analysis, the hypothesis was adopted that opinions concerning health risk related with work in the coal mine are significantly related with the age of the examined employees, their education and position occupied. A basis for such assumptions is the belief that more experienced 


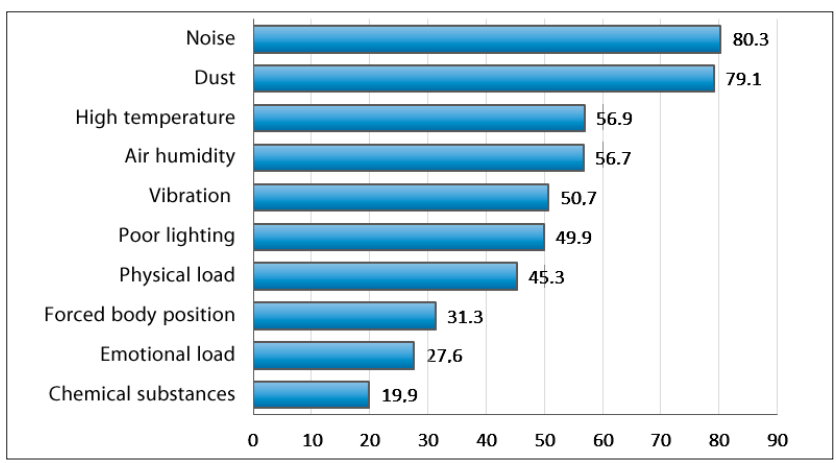

Figure 1. Factors of the work environment exerting a negative effect on the state of health in opinions of employees performing work underground (\% of respondents indicating an individual factor)

persons possessing higher education level more accurately identify health hazards. However, it seems that the position held is of essential importance in the way of perceiving health hazards at the workplace. This results from the specificity of an individual workplace, including the character of the work performed, tools used for its performance, environmental conditions in which the work is performed, and work organization.

Analysis of data showed that the age of the employees of 'Bogdanka' mine is related with only some of the opinions concerning the factors of work environment exerting an effect on health. In individual age categories, statistically significant differences were observed with respect to five (per 10) factors creating health risk: dust, noise, vibration, humidity, and poor lighting (Tab. 1). All these factors were indicated by a significantly higher percentage of employees aged from 31-40 than in the remaining age categories. The hazardous effect of dustiness at the workplace was reported by $90 \%$ of the employees in the coal mine aged $31-40$. This hazard was mentioned by a slightly lower percentage of the youngest respondents (82.1\%) and a considerably lower percentage of those aged over 40 (approximately 75\%). Statistically significant differences were observed on the

Table 1. Factors of work environment exerting a negative effect on the state of health in opinions of examined underground workers in a coal mine, according to age

\begin{tabular}{|c|c|c|c|c|c|c|c|c|}
\hline \multirow{4}{*}{ Type of hazard } & \multicolumn{8}{|c|}{ Age } \\
\hline & \multicolumn{2}{|c|}{$21-30$} & \multicolumn{2}{|c|}{$31-40$} & \multicolumn{2}{|c|}{$41-50$} & \multicolumn{2}{|c|}{51 and over } \\
\hline & & $\%$ & & $\%$ & & $\%$ & & $\%$ \\
\hline & $\mathrm{N}$ & $\mathrm{n}=112$ & $\mathrm{~N}$ & $n=207$ & $\mathrm{~N}$ & $\mathrm{n}=348$ & $\mathrm{~N}$ & $n=33$ \\
\hline Dust** & 92 & 82.1 & 180 & 90.0 & 257 & 73.8 & 25 & 75.8 \\
\hline Noise ${ }^{* *}$ & 87 & 77.7 & 182 & 87.9 & 270 & 77.6 & 23 & 69.7 \\
\hline Vibration** & 57 & 50.9 & 122 & 58.9 & 166 & 47.7 & 10 & 30.3 \\
\hline Air humidity* & 56 & 50.0 & 136 & 65.7 & 187 & 53.7 & 18 & 54.5 \\
\hline High temperature & 59 & 52.7 & 132 & 63.8 & 191 & 54.9 & 16 & 48.5 \\
\hline Poor lighting ${ }^{* *}$ & 51 & 45.5 & 125 & 60.4 & 161 & 46.3 & 12 & 36.4 \\
\hline Physical load & 50 & 44.6 & 108 & 52.2 & 147 & 42.2 & 12 & 36.4 \\
\hline Emotional load & 21 & 18.7 & 63 & 30.4 & 99 & 28.4 & 10 & 30.3 \\
\hline Chemical substances & 17 & 15.2 & 44 & 21.3 & 70 & 20.1 & 8 & 24.2 \\
\hline Forced body position & 31 & 27.7 & 72 & 34.8 & 109 & 31.3 & 7 & 21.2 \\
\hline
\end{tabular}

Percentages do not sum-up to $100 \%$, because a respondent could select more than one hazard. $\mathrm{N}$ - numbers of respondents indicating a specified type of hazard; $\mathrm{n}$ - numbers of subgroup (total) ${ }^{*} p<0.05 ; * p<0.01$; lack of asterisk $-p \geq 0.05$ level of $p<0.01$. A similar scale of differences was found with respect to the occurrence of noise, vibration, and poor lighting at the workplace. These factors were also most frequently indicated by employees aged 31-40. These three factors (noise, vibration, and poor lighting) were reported by a slightly lower percentage of respondents from two age categories - 21-30 and 41-50. It is an interesting result that in both age categories the percentages of indications of these two types of hazards were similar (Tab. 1). The lowest awareness of the occurrence of these factors was observed among respondents in the oldest age group (over 50). Employees at this age twice as rarely as those aged $31-40$ mentioned vibration as a factor hazardous for health (58.9\% and 30.35\%, respectively). Similar proportions occurred in both groups in the case of opinions that poor lighting is a health risk factor (60.4\% and $36.4 \%$, respectively). Statistically significant differences were also noted with respect to opinions that humidity of the air exerts a negative effect on the health of employees working in the coal mine. This was admitted by two-thirds of respondents aged 31-40 (65.7\%), and a considerably lower percentages in the older age categories (53.7\% of employees aged $41-50$ and $54.5 \%$ of those aged 51 or older). In the youngest age category, humidity of the air as a health risk factor was indicated by the lowest percentage of respondents (50.0\%).

The majority of opinions of the examined miners concerning the factors exerting a negative effect on their health while performing work did not significantly differ in the subgroups of different levels of education. Hazards such as dust, high humidity of the air, high temperature, poor lighting, and exposure to chemical agents, was reported by a similar percentages of respondents with university, secondary school, elementary vocational and primary education (Tab. 2). Statistically significant differences were observed only with respect to the opinion that health risk is related with a high physical load at work, emotional load, vibration and noise. The greatest differences were found between evaluations of risk related with loading with physical work $(\mathrm{p}<0.001)$.

Table 2. Factors of work environment exerting a negative effect on the state of health in opinions of examined underground workers in a coal mine, according to education level

\begin{tabular}{|c|c|c|c|c|c|c|}
\hline \multirow{3}{*}{ Type of hazard } & \multicolumn{6}{|c|}{ Education level } \\
\hline & \multicolumn{2}{|c|}{ university } & \multicolumn{2}{|c|}{ secondary } & \multicolumn{2}{|c|}{$\begin{array}{c}\text { elementary } \\
\text { vocational and } \\
\text { primary }\end{array}$} \\
\hline & $\mathrm{N}$ & $\begin{array}{c}\% \\
\mathrm{n}=92\end{array}$ & $\mathrm{~N}$ & $\begin{array}{c}\% \\
n=209\end{array}$ & $\mathrm{~N}$ & $\begin{array}{c}\% \\
n=399\end{array}$ \\
\hline Dust & 69 & 75.0 & 177 & 84.7 & 308 & 77.2 \\
\hline Noise* & 68 & 73.9 & 179 & 85.6 & 315 & 78.9 \\
\hline Vibration $* *$ & 28 & 30.4 & 120 & 57.4 & 207 & 51.9 \\
\hline Air humidity & 51 & 55.4 & 122 & 58.4 & 224 & 56.1 \\
\hline High temperature & 50 & 54.3 & 123 & 58.9 & 225 & 56.4 \\
\hline Poor lighting & 45 & 48.9 & 117 & 56.0 & 187 & 46.9 \\
\hline Physical load ** & 23 & 25.0 & 102 & 48.8 & 192 & 48.1 \\
\hline Emotional load ** & 40 & 43.5 & 51 & 24.4 & 102 & 25.6 \\
\hline Chemical substances & 25 & 27.2 & 78 & 37.3 & 116 & 29.1 \\
\hline
\end{tabular}

Percentages do not sum-up to $100 \%$. because a respondent could select more than one hazard. $\mathrm{N}$ - numbers of respondents indicating a specified type of hazard; $\mathrm{n}$ - numbers in subgroup (total) ${ }^{*} p<0.05 ;{ }^{* *} p<0.01$; lack of asterisk $-p \geq 0.05$ 
Nearly a half of respondents with secondary school education (48.8\%), and elementary vocational and primary education (48.1\%) admitted that a high physical load at work is the factor negatively affecting their health, whereas a twice as low percentage of respondents with university education mentioned this type of risk (25.0\%). Opposite proportions of replies were found in the case of opinions that emotional load exerts a negative effect on employees performing work underground. This type of risk was significantly more often $(\mathrm{p}<0.01)$ reported by respondents with university education (43.5\%) than those with a lower education level (secondary school $-24.4 \%$, elementary vocational and primary education - 25.6\%). Based on the observed relationships, it may be presumed that the way of evaluation of health hazards at workplaces underground was more related with the position held than the education level. Employees with university education usually held management positions and tended not to be engaged in hard physical work; thus, perceive risk on the part of physical load to a lower degree. Simultaneously, responsibility due to the function performed is undoubtedly related with a higher emotional load. Due to the character of the work of employees with a lower education level, their perception of health hazards differs from that of the management staff.

A relatively low percentage of respondents with university education perceived health risk on the part of vibration at the workplace (30.4\%). This risk was indicated by a considerably higher percentage of workers with the lowest level of education (51.9\%), and the highest percentage of employees with secondary school education (statistically significant differences $\mathrm{p}<0.01$ ). A similar direction of relationships was found with respect to opinions concerning a negative effect of noise on the health of miners working underground. This risk was reported by $85.6 \%$ of respondents with secondary school education, slightly less among those with a low education level (78.9\%), while the smallest percentage was among those with university education $(73.9 \%$; $\mathrm{p}<0.05)$.

A previously posed hypothesis was confirmed, that the greatest differences in opinions concerning the factors threatening health at workplaces are found in the subgroups of respondents holding various work positions. Only with respect to the three evaluated factors (noise, poor lighting, and forced body position at work) the opinions of respondents holding different work positions were similar (lack of statistically significant differences). The opinions pertaining to the effect on health of the remaining factors (7 per 10 of those evaluated) significantly differed according to the position held (Tab. 3). The data presented in Table 3 demonstrate that employees working at the position of a miner, significantly more often than the remainder, perceived health risk on the part of such factors as: vibration, high temperature, high physical load, and chemical substances. The greatest differences in the way of perceiving these hazards were observed while comparing the opinions of miners and workers employed at positions of mining supervision. Vibration was the factor exerting a negative effect on health was mentioned by $54.6 \%$ of miners, a slightly lower percentage of respondents employed at other workplaces $(46.0 \%)$, and a three times lower percentage of employees of mining supervision $(\mathrm{p}<0.01)$. Even greater disproportions were observed with respect to risk related with chemical substances. This factor was reported by $22.0 \%$ of miners, and a more than five times lower percentage of employees
Table 3. Factors of work environment exerting a negative effect on the state of health in opinions of examined underground workers in a coal mine, according to workplace

\begin{tabular}{lcccccc}
\hline & \multicolumn{7}{c}{ Workplace } \\
\cline { 2 - 7 } Type of hazard & \multicolumn{2}{c}{ supervision } & \multicolumn{2}{c}{ miner } & \multicolumn{2}{c}{ other } \\
\cline { 2 - 8 } & $\mathrm{N}$ & $\begin{array}{c}\% \\
\mathrm{n}=43\end{array}$ & $\mathrm{~N}$ & $\mathrm{n}=518$ & $\mathrm{~N}$ & $\mathrm{n}=139$ \\
\hline Dust* $^{*}$ & 33 & 76.7 & 424 & 81.8 & 97 & 69.8 \\
\hline Noise & 29 & 67.4 & 424 & 81.8 & 109 & 78.4 \\
\hline Vibration** & 8 & 18.6 & 283 & 54.6 & 64 & 46.0 \\
\hline Air humidity* & 28 & 65.1 & 305 & 58.9 & 64 & 46.0 \\
\hline High temperature** & 23 & 53.5 & 315 & 60.8 & 60 & 43.2 \\
\hline Poor lighting & 18 & 41.9 & 267 & 51.5 & 64 & 46.0 \\
\hline Physical load** & 5 & 11.6 & 267 & 51.5 & 45 & 32.4 \\
\hline Emotional load** & 29 & 67.4 & 132 & 25.5 & 32 & 23.0 \\
\hline Chemical substances* $^{*}$ & 2 & 4.6 & 114 & $22.0 \%$ & 23 & 16.5 \\
\hline Forced body position & 10 & 23.3 & 172 & 33.2 & 37 & 26.6 \\
\hline
\end{tabular}

Percentages do not sum-up to $100 \%$. because a respondent could select more than one hazard. $\mathrm{N}$-numbers of respondents indicating a specified type of hazard; $\mathrm{n}$-numbers in subgroup (total) ${ }^{*} \mathrm{p}<0.05 *{ }^{*} \mathrm{p}<0.01$; lack of asterisk $-\mathrm{p} \geq 0.05$

of mining supervision (4.6\%). In turn, employees of mining supervision more frequently than the remainder admitted that high humidity of the air (65.1\%) and emotional load (67.4\%) negatively affect their health. High humidity of the air as a risk factor was indicated by a slightly lower percentage of miners, and the lowest percentage of persons employed at other workplaces $(\mathrm{p}<0.05)$. Miners and respondents employed at other workplaces nearly three times less often perceived risk on the part of emotional load, compared to the employees of mining supervision (25.5\% of miners, $23.0 \%$ of other workplaces, $76.4 \%$ of mining supervision) $(\mathrm{p}<0.01)$.

\section{DISCUSSION}

The process of coal mining is accompanied by many hazards which are the source of risk, may negatively affect the life and health of employees, and lead to high material loss $[28,29$, 30]. Exposure of workers to crystalline silica present in dust produced as a result of coal mining is especially unfavourable for health $[29,31,32,33,34,35]$.

The presented study showed that employees who perform work underground in the 'Bogdanka' coal mine more frequently reported dust as the factor exerting a negative effect on their health. The accuracy of these opinions is confirmed by data concerning morbidity among miners in Poland. During the period 2000-2017, as many as 7,340 cases of pneumoconiosis were noted among present and ex-miners [36]. In 2016, 603 cases of pneumoconiosis were registered $(28.5 \%$ of all diseases related with health risk). Pneumoconiosis was the most frequently diagnosed occupational disease. From the total number of registered cases of pneumoconiosis, the majority were cases among coal miners - $466(77.3 \%)$, whereas the remainder, i.e. pneumoconiosis - 83 cases (13.8\%), and asbestosis - 36 cases (5.9\%) [37]. Pneumoconiosis is the most frequent occupational disease, not only among coal miners in Poland, but also in China and the USA [38].

According to own study, noise and vibration are serious hazards in the opinions of miners. Measurements of whole 
body vibration performed among operators of mining vehicles and equipment in three mines (Finland, Norway, Sweden) unequivocally confirmed that exposure to vibration may constitute a serious health risk, which should not be ignored [39].

Noise at the workplace may be the factor which makes the work arduous, and simultaneously may cause negative health effects. According to the data by the World Health Organization (WHO), 16\% of hearing loss among workers is caused by occupational noise [40]. Noise-induced hearing loss (NIHL) occurs as a result of exposure to noise of a high level $(>85 \mathrm{~dB})$ at the workplace [8]. Negative effect of noise at work was compared in own study which showed that the vast majority of miners (approximately $80 \%$ ) considered this factor as hazardous for health.

Unfavourable microclimate and lighting, the factors exerting a negative effect on health at the workplace, were relatively often reported by the examined miners. This results from conditions present in coal mines. In Polish coal mining, the depth at which mining work is performed is increasing, as well as the concentration of production, which causes, among others, an increase in climatic risk. Human functioning in conditions of a hot microclimate depends on the possibilities of maintaining a sustained heat balance. In mining, the heat load to which employees are exposed results from both intensity of metabolism while performing hard physical work, and conditions of the external environment [41].

High humidity of the air is the element of microclimate. This health risk factor was indicated especially by employees performing work underground at workplaces of mining supervision. Sunkpal et al., in their study analyzed the effect of changing humidity, air velocity, pace of metabolism and air temperature on the heat comfort of miners. Multivariate analyzes showed that humidity most negatively affected the deviations from heat comfort [14].

Workers employed in mines are exposed to various types of chemical substances [3]. In the current study, chemical substances present at the workplace which exert a negative effect on health were most rarely mentioned.

\section{CONCLUSIONS}

It was found that in the opinions of respondents employed in coal mines, noise and dust at the workplace are the factors most hazardous for health. Workers employed at the workplace of a miner, aged 31-40, with secondary school education, most often complained of these factors. Analyses of opinions concerning health hazards at the workplace according to such independent variables as: age, education and position held, demonstrated that the greatest differences in opinions concerning this problem were observed according to the position held. The obtained results allow the presumption that miners are the group most exposed to the hazardous effect of the workplace. In the group of employees of mining supervision, a specific health hazard is emotional load which, as it should be presumed, results from performing a managerial function.

The majority of health hazards at workplaces in coal mines result from the technology of mining. It seems justifiable to introduce increasingly newer solutions in the process of coal mining in order to minimize the occurrence of these factors at work and, consequently, their negative effect on the health of employees performing work underground in coal mines. In addition, it seems necessary to implement new, more effective educational programmes aimed at imparting knowledge concerning the occurrence of factors hazardous for health at workplaces, as well as health consequences for the lack of observance of the OSH principles at the workplace. The shaping of the skills of identification of hazards and recognition of early symptoms of diseases related with unfavourable work conditions in mining is an important element of education in this area.

\section{REFERENCES}

1. Amponsah-Tawiah K, Mensah J. Occupational Health and Safety and Organizational Commitment: Evidence from the Ghanaian Mining Industry. Saf Health Work. 2016 Sep; 7(3): 225-30. doi: 10.1016/j. shaw.2016.01.002. Epub 2016 Feb 2.

2. International Labour Organinization. Mining: a hazardous work [Internet]. 2015 [cited 2015 Feb 2]. Available from: http://www.ilo. org/safework/areasofwork/hazardous-work/WCMS_124598/lang-en/ index.htm.

3. Gyekye SA. Workers' perceptions of workplace safety: an African perspective. Int J Occup Saf Ergon. 2006; 12: 31e42.

4. Salas ML, Quezada S, Basagoitia A, Fernandez T, Herrera R, Parra M, Muñoz DM, Weigl M, Radon K. Working Conditions, Workplace Violence, and Psychological Distress in Andean Miners: A Crosssectional Study Across Three Countries. Ann Glob Health. 2015 JulAug; 81(4): 465-74. doi: 10.1016/j.aogh.2015.06.002.

5. Donoghue AM. Occupational health hazards in mining: an overview. Occup Med. (Lond) 2004; 54: 283e9.

6. Kurmis AP, Apps SA. Occupationally-acquired noise-induced hearing loss: a senseless workplace hazard. Int J Occup Med Environ Health. 2007; 20: 127e36.

7. McBride DI. Noise-induced hearing loss and hearing conservation in mining. OccupMed. (Lond) 2004; 54: $290 \mathrm{e} 6$.

8. Jain RK, Pingle SK, Tumane RG, Thakkar LR, Jawade AA, Barapatre A, Trivedi M. Cochlear Proteins Associated with Noise-induced Hearing Loss: An Update. Indian J Occup Environ Med. 2018 May-Aug; 22(2): 60-73. doi: 10.4103/ijoem.IJOEM_43_18.

9. Mo JF, Wang L, Au W, Su M. Prevalence of coal workers' pneumoconiosis in China: a systematic analysis of 2001-2011 studies. Int J Hyg Environ Health. 2014; 217: 46-51. https://doi.org/10.1016/j.ijheh.2013.03.006 PMID: 23608000

10. Barber C, Fishwick D. Pueumoconiosis. Med. 2016; 44: 355-358.

11. Han F, Liu J. Flow field characteristics and coal dust removal performance of an arc fan nozzle used for water spray. PLoS One. 2018 Sep 20; 13(9): e0203875. doi: 10.1371/journal.pone.0203875. eCollection 2018.

12. Handbook AF. American society of heating, refrigerating and airconditioning engineers. Inc.: Atlanta; 2007.

13. Handbook AF. American society of heating, refrigerating and airconditioning engineers. Inc.: Atlanta; 2009.

14. Sunkpal M, Roghanchi P, Kocsis KC. A Method to Protect Mine Workers in Hot and Humid Environments. Saf Health Work. 2018 Jun; 9(2): 149-158. doi: 10.1016/j.shaw.2017.06.011. Epub 2017 Jul 13.

15. Chau N. Injury proneness. In: Cooper CL, Burke RJ, Clarke S, editors. Occupational Health and Safety. Series Psychological and behavioural of risks. Surrey, Burlington: Gower Publishing Ltd.; 2011. p. 119-36.

16. Chau N, Gauchard G, Dehaene D, Benamghar L, Touron C, Perrin $\mathrm{P}$, et al. Contributions of occupational hazards and human factors in occupational injuries and their associations with job, age and type of injuries in railway workers. Int Arch Occup Environ Health. 2007; 80: 517-25, http://dx.doi. org/10.1007/s00420-006-0158-8.

17. Chau N, Mur JM, Benamghar L, Siegfried C, Dangelzer JL, Français $\mathrm{M}$, et al. Relationships between certain individual characteristics and occupational accidents for various jobs in the construction industry: A case-control study. Am J Ind Med. 2004; 45: 84-92, http://dx.doi. org/10.1002/ ajim.10319.

18. Dembe AE, Erickson JB, Delbos RG, Banks SM. The impact of overtime and long work hours on occupational injuries and illnesses: new evidence from the United States. Occup Environ Med. 2005; 62: 588-97, http://dx.doi.org/10.1136/ oem.2004.016667. 
19. Melamed S, Yekutieli D, Froom P, Kristal-Boneh E, Ribak J. Adverse work and environmental conditions predict occupational injuries. The Israeli cardiovascular occupational risk factors determination in Israel (CORDIS) study. Am J Epidemiol. 1999; 150: 18-26, http://dx.doi. org/10.1093/oxfordjournals.aje.a009913.

20. Sprince NL, Park H, Zwerling C, Lynch CF, Whitten PA, Thu K, et al. Risk factors for machinery-related injury among Iowa farmers: a casecontrol study nested in the Agricultural Health Study. Int J Occup Environ Health. 2002; 8:332-8.

21. Kunar BM, Bhattacherjee A, Chau N. A matched case-control study of occupational injury in underground coalmine workers. J Southern African Institute of Mining and Metallurgy. 2010; 110: 1-9.

22. Bhattacherjee A, Bertrand JP, Meyer JP, Benamghar L, Otero Sierra C, Michaely JP, et al. Relationships of physical job tasks and living conditions with occupational injuries in coal miners. Ind Health. 2007; 45: 352-8, http://dx.doi. org/10.2486/indhealth.45.352.

23. Bhattacherjee A, Kunar BM, Baumann M, Chau N; Lorhandicap Group. The role of occupational activities and work environment in occupational injury and interplay of personal factors in various age groups among Indian and French coalminers. Int J Occup Med Environ Health. 2013 Dec; 26(6): 910-29. doi: 10.2478/s13382-013-0165-4. Epub 2014 Jan 25.

24. Centers for Disease Control and Prevention. National Occupational Mortality Surveillance. US Department of Health and Human Services. Available at: http://www.cdc.gov/niosh/topics/surveillance/noms/ description.html. Accessed September 2013

25. Yeoman KM, Halldin CN, Wood J, Storey E, Johns D, Laney AS.:Current knowledge of US metal and nonmetal miner health: Current and potential data sources for analysis of miner health status. Arch Environ Occup Health. 2016; 71(2): 119-26. doi:10.1080/19338244.2014.99833 0 . Epub 2015 Feb 6.

26. Centers for Disease Control and Prevention. MSHA data file downloads. US Department of Health and Human Services. Available at: http:// www.cdc.gov/niosh/mining/data/default.html. Accessed July 2013.

27. Sprawozdanie Zarządu z działalności Lubelski Węgiel Bogdanka S.A.za okres od 1 stycznia 2009 roku do 31 grudnia 2009, Bogdanka marzec 2010 (in Polish).

28. Canadian Centre for Occupational Health and Safety. Hazard and Risk. Available online: https://www. ccohs.ca/Oshanswers/hsprograms/ hazard_risk.html (accessed on 27 July 2018).
29. Brodny J, Tutak M. Exposure to Harmful Dusts on Fully Powered Longwall Coal Mines in Poland. Int J Environ Res Public Health. 2018 27; 15(9). pii: E1846. doi: 10.3390/ijerph15091846.

30. Tynan et al. Help-seeking for mental health problems by employees in the Australian Mining Industry. BMC Health Serv Res. 2016; 16: 498 DOI 10.1186/s12913-016-1755-1.

31. Nie W, Cheng WM, Zhou G, Xie J, Cui XF. Experimental study on spray atomized particle size affected by airflow disturbance in heading face. J China Univ Min Technol. 2012; 41: 378-383.

32. Castranova V, Vallyathan V. Silicosis and coal workers' pneumoconiosis. Environ Health Perspect. 2000; 108 (Suppl. 4): 675-684.

33. Tan C, Jiang ZA. Similarity experiment on muti-source dust diffusion law in fully mechanized caving face. J China Coal Soc. 2015; 40: 122-127.

34. Zhou G, Cheng WM, Wang G, Cui XF. Experiment research of the coupling relationship between dust field and droplet field about fully mechanized and roof caving work face. J China Coal Soc. 2010; 35: 1660-1664.

35. Wanxing Ren, Jingtai Shi, Qing Guo, Qiankun Zhao, Lei Bai. The influence of dust particles on the stability of foam used as dust control in underground coal mines. Proc Safety Environ Protect. 2017; 111: 740-746. http://dx.doi.org/10.1016/j.psep.2017.08.043

36. Świątkowska B, HankeW, Szeszenia-Dąrowska N. Occupational Diseases in Poland in 2016. Nofer Institute of Occupational Medicine: Łódź, Poland, 2017.

37. Świątkowska B, Hanke W. Occupational diseases in Poland in 2016. Med Pr. 2018 pii: 92434. doi: 10.13075/mp.5893.00745 (in Polish).

38. National Bureau of Statistics of China (NBSC). The Portion of Energy Consumption. Available online:http://www.stats.gov.cn/tjsj/ndsj/2017/ indexch.htm (accessed on 5 June 2018).

39. Burström L, Hyvärinen V, Johnsen M, Pettersson H. Exposure to whole-body vibration in open-cast mines in the Barents region. Int J Circumpolar Health. 2016; 75: 29373. doi: 10.3402/ijch.v75.29373. eCollection 2016.

40. World Health Organization (WHO) report 2001. Available from www. who.int/quantifying_ehimpacts/global/ebdcountgroup/en/index.html 2001. [Last accessed on 2015 Jun 15].

41. Tynan RJ, James C, Considine R, Skehan J, Gullestrup J, Lewin TJ, Wiggers J, Kelly BJ. Feasibility and acceptability of strategies to address mental health and mental ill-health in the Australian coal mining industry. Int J Ment Health Syst. 2018; 12: 66. doi: 10.1186/s13033018-0245-8. eCollection 2018.

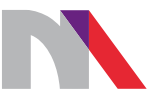

Ministry of Science and Higher Education

Republic of Poland

Generation of the DOI (Digital Object Identifier) - task financed under the agreement No. 618/P-DUN/2019 by the Minister of Science and Higher Education 